\title{
MicroRNA expression profiles associated with acquired gefitinib-resistance in human lung adenocarcinoma cells
}

\author{
XIAOJUN GE ${ }^{1,2}$, LIMEI ZHENG ${ }^{2}$, MIN HUANG ${ }^{3}$, YONGLUN WANG ${ }^{2}$ and FENG BI ${ }^{1}$ \\ ${ }^{1}$ Department of Medical Oncology and Laboratory of Signal Transduction and Molecular Targeted Therapy, \\ State Key Laboratory of Biotherapy, West China Hospital, Sichuan University, Chengdu, Sichuan 610041; \\ ${ }^{2}$ Department of Laboratory Medicine, Affiliated Hospital of Zun Yi Medical College, Zun Yi, Guizhou 563003; \\ ${ }^{3}$ Department of Occupational and Environmental Health, School of Public Health, \\ Ningxia Medical University, Ningxia 750004, P.R. China
}

Received January 6, 2014; Accepted September 18, 2014

DOI: $10.3892 / \mathrm{mmr} .2014 .2757$

\begin{abstract}
The aim of the present study was to establish, characterize and elucidate the potential mechanisms of acquired gefitinb resistance, using the A549 human lung cancer cell line. A gefitinib-resistant A549 sub-clone was established by exposure to escalating gefitinib concentrations over a period of 16-24 months. Half maximal inhibitory concentration $\left(\mathrm{IC}_{50}\right)$ values were quantified using a real time cytotoxicity assay. The expression profiles of the parent and resistant sub-clone A549 cells were detected using the $\mu$ Paraflo ${ }^{\circledR}$ Microfluidics Biochip microRNA (miRNA) Microarray. The ArrayPro software was used to analyze the differential expression levels of the miRNA, and bioinformatics software was used to predict the potential target genes of the differentially expressed miRNAs. Quantitative polymerase chain reaction (qPCR) was used to confirm the results of the miRNA microarray. A miRNA mimic was transfected into the gefitinib-resistant cells, in order to predict target gene interaction effects, following gefitinib treatment. Protein expression level differences were confirmed by western-blot analysis. Real time cytotoxicity assays revealed a 3 -fold increase in the $\mathrm{IC}_{50}$ values of the gefitinib-resistant sub-clones, as compared with the parent cells. There were marked morphological differences between the parent and resistant cells. In the microarray analysis, the gefitinib-resistant sub-clones had 25 upregulated and 18 downregulated miRNAs, as compared with the parent cells. The qPCR revealed that miR-7 was
\end{abstract}

Correspondence to: Professor Feng Bi, Laboratory of Signal Transduction and Molecular Targeted Therapy/Department of Medical Oncology, West China Hospital, Sichuan University, 37 Guo Xue Xiang, Chengdu, Sichuan 610041, P.R. China

E-mail: bifeng@medmail.com.cn

Key words: lung cancer, drug resistance, microRNAs, microarray, gefitinib significantly downregulated, which was concordant with the results of the microarray. The results of the present study suggest that miR-7 may significantly improve the sensitivity of cancer cells to gefitinib. The data presented in the present study provides an experimental basis and theory that miRNAs may be involved in acquired gefitinib-resistance of lung adenocarcinoma, and miR-7 may have potential clinical effects in the reversal of drug resistance.

\section{Introduction}

Lung cancer remains the leading cause of cancer-associated mortality in the world. The majority of patients are initially diagnosed with advanced disease, or develop recurrence, neither of which is amenable to curative approaches (1). Previous studies have demonstrated that gefitinib is a promising therapeutic agent for the treatment of a wide range of tumors, including non-small-cell lung cancer (NSCLC). Gefitinib inhibits the autophosphorylation of epidermal growth factor (EGF)-stimulated EGF receptor (EGFR), in various EGFR-expressing human cancer cell lines (2). Activation of EGFR leads to receptor associated tyrosine kinase (TK) activity, that initiates a cascade of events leading to downstream signaling and numerous changes characteristic of malignant progression. This results in the enhancement of cellular growth and invasive capacity. Preclinical data has indicated that gefitinib competes with adenosine triphosphate for delivery of phosphate groups to critical tyrosine residues, and this may prevent signal transduction through EGFR (3). Four phase I studies have shown that gefitinib is generally well tolerated, with evidence of antitumor activity in NSCLC, and two large phase II gefitinib monotherapy studies, in patients with pretreated advanced NSCLC, have further confirmed that gefitinib is generally well tolerated and has clinically significant antitumor activity $(4,5)$. Therapeutic responses to EGFR-TK inhibitors may persist for as long as 2-3 years; however, drug resistance eventually emerges and this limits the mean duration of response to 6-8 months $(6,7)$. 
Micro (mi)RNAs have been reported to participate in lung cancer oncogenesis $(8,9)$. MiRNAs are small, endogenous, non-coding RNAs, which are highly conserved and have been identified as a powerful tool for regulating gene expression through the RNA interference pathway $(10,11)$. With the ability of one miRNA to bind and regulate numerous mRNAs, and the potential for a single mRNA to be targeted by numerous miRNAs, it is possible to fine-tune the expression of proteins within the cell in a very precise manner (12). Recent advances in bioinformatics and high-throughput technologies, such as microarray analysis, are increasing the understanding of the molecular mechanisms underlying drug sensitivity and biological processes (13). In the present study, gefitinib resistant sub-clone A549 cells were established, and miRNA expression microarray analyses and functional studies were performed, to determine the molecular mechanisms of the chemoresistance of NSCLC.

\section{Materials and methods}

Cell culture. The A549human lung cancercell line was purchased from American Type Culture Collection (Manassas, VA, USA). The cells were cultured in RPMI-1640 (Life Technologies, Grand Island, NY, USA), supplemented with $10 \%$ fetal bovine serum (FBS; Life Technologies) and 1\% penicillin/streptomycin (Life Technologies) at $37^{\circ} \mathrm{C}$ in $5 \% \mathrm{CO}_{2}$. The cells were grown as monolayers in $75 \mathrm{~cm}^{2}$ cell culture flasks, unless otherwise stated. All of the cell lines tested negative for mycoplasma contamination, using polymerase chain reaction (PCR) methods (14), and were authenticated using Short Tandem Repeats testing. Gefitinib was purchased from AstraZeneca (Macclesfield, UK). The primary antibody used for the western blot analysis was a rabbit monoclonal anti-EGFR antibody (Abcam, Cambridge, MA, USA).

Establishment of gefitinib-resistant sub-clones from parent (control) cell lines. To develop gefitinib-resistance, the A549 cells were continually exposed to stepwise increases in the concentration of gefitinib over a period of 16-24 months. Briefly, the cells were seeded at a density of $\sim 5 \times 10^{5} / \mathrm{ml}$, in a T75 cell culture flask with $10 \mathrm{ml}$ complete growth medium. Following a 4-6 h of incubation, relatively low concentrations of gefitinib, starting at $0.01 \mu \mathrm{g} / \mathrm{ml}$, were dissolved in phosphate-buffered saline (PBS), without $\mathrm{Ca}^{2+}$ and $\mathrm{Mg}^{2+}$, and added to the medium. The cells remained in the gefitinib-supplemented media for 2-4 weeks, or until a stable cell re-population had formed. Regular medium replenishment was performed throughout this period. The gefitinib concentration was then increased by 0.5 to 2 fold. The stepwise dose escalation continued for 16-24 months, until the gefitinib concentration had reached $\geq 10 \times$ the starting concentration. Thereafter, gefitinib-resistant cell lines were maintained in their highest achieved gefitinib concentration. Concurrently, regular passage of the parent cells was conducted.

Gefitinib sensitivity test. Prior to the gefitinib resistance/sensitivity assessment (cytotoxicity assay), a cell proliferation assay was carried out using the xCELLigence system (Roche Diagnostics, South San Francisco, CA USA). The cell proliferation assay was performed to identify the optimal conditions under which the real-time cytotoxicity assay should be conducted. The proliferation assay was used to identify the optimal seeding density for the cytotoxicity assay for each of the cell lines, and to determine the duration of the cytotoxicity assay.

The proliferation assay was carried out by seeding various densities of cells into a 96-well plate (E-plate 96; Roche) in quadruplicate, followed by real time monitoring of cellular growth for up to seven days. After $24 \mathrm{~h}$ half of the wells on the plate were treated with gefitinib, in order to determine the cellular response. The proliferation assay was repeated twice on each cell line. Optimal seeding densities for each line were selected based on the marked changes in proliferation observed 72-96 $\mathrm{h}$ following gefitinib treatment, and small variations across the replicate wells.

For the cytotoxicity assays, a cell count was initially performed, the cells were then seeded in triplicate wells with $180 \mu 1$ gefitinib-free cell culture medium, in a 96-well plate. After $24 \mathrm{~h}, 20 \mu \mathrm{l}$ cell culture medium, containing serially diluted gefitinib ranging from $0-800 \mu \mathrm{g} / \mathrm{ml}$, was added to each well. The number of viable cells was monitored every $15 \mathrm{~min}$, for a total of $\geq 120 \mathrm{~h}$. Half maximal inhibitory concentration $\left(\mathrm{IC}_{50}\right)$ values of the gefitinib-resistant and parent (control) cells were subsequently calculated using the integrated software of the xCELLigence system.

Morphologic analysis. The cells were grown in a chamber slide (Nalge Nunc International, Naperville, IL, USA) and stained with hematoxylin \& eosin. The cells were visualized using a Nikon light microscope (Nikon, Inc., Melville, NY, USA) with digital photographic capability.

MiRNA expression profiling. A microarray was performed using a $\mu$ Paraflo ${ }^{\circledR}$ Microfluidics Biochip (LC Sciences, Houston, TX, USA). The microarray probe sequence was derived from Sanger MiBase version 15.0 (http://microrna.sanger.org). Each chip contained multiple quality control probes and used a dual-color chip to examine miRNA expression profiling in the gefitinib-resistant and parent A549 cells. The probes were synthesized using a photosensitive PCR. The sequence consisted of two fragments: A chemically modified oligonucleotide encoding a fragment complementary to the target miRNA or target RNA, and an extension arm at a certain distance from the connected encoding sequence, which lessened the hybridization spatial impairment. The melting temperature of the probe hybridization was balanced by chemical modification. Total RNA was extracted with TRIzol (Life Technologies) according to the manufacturer's instructions, and the RNA intergrity number was determined by Bioanalyzer (Agilent, Santa Clara, CA, USA). RNA samples (5 $\mu \mathrm{g})$ were filtered through a YM-100 micro centrifuge column (EMD Millipore, Billerica, MA, USA) to produce small RNA (<300 nt). Poly (A) polymerase was used to add a poly(A) tail to the 3' end of small RNA, and an oligonucleotide marker was used for further fluorescent labelling. Two types of marker were used to label the matched RNA samples. The hybridization was completed on the $\mu$ Paraflo ${ }^{\circledR}$ Microfluidics Biochip using a micro circulation pump (Atactic Technologies Inc., Houston, TX, USA). The hybridization mix contained $100 \mu 16$ X SSPE buffer (0.90 M NaCl, $60 \mathrm{mM} \mathrm{Na}_{2} \mathrm{HPO}_{4}, 6$ mM EDTA, pH 6.8) 
with $25 \%$ formaldehyde, at a temperature of $34^{\circ} \mathrm{C}$. The $\mathrm{Cy} 3$ and Cy5 specific fluorescent labels and the Axon GenePix ${ }^{\circledR}$ 4000B microarray scanner (Molecular Devices, Sunnyvale, CA, USA) were used to capture the hybridization images. ArrayPro (Media Cybernetics, Inc., Rockville, MD, USA) was used to complete the digital transformation.

Quantitative PCR ( $P$ PCR) validation for miRNA expression profiling. A qPCR was performed to validate the differential miRNA expression profiles obtained from the microarray analysis. Total RNA was extracted with TRIzol (Life Technologies) according to the manufacturer's instructions, and the RNA intergrity number was determined by Bioanalyzer (Agilent, Santa Clara, CA, USA). Total RNA was reverse-transcribed into cDNA using AMV Reverse Transcriptase (RT), RNase (Epicentre, Madison, WI, USA), dNTP (HyTest Ltd, Turku, Finland), RT buffer, and RT primers (Invitrogen Life Technologies, Carlsbad, CA, USA). The mixture was incubated at $16^{\circ} \mathrm{C}$ for $30 \mathrm{~min}, 42^{\circ} \mathrm{C}$ for $40 \mathrm{~min}$, and $85^{\circ} \mathrm{C}$ for $5 \mathrm{~min}$ to generate a library of miRNA cDNAs. U6 was used as the internal control for normalization. The qPCR was subsequently performed using an ABI PRISM ${ }^{\circledR} 7900$ system (Applied Biosystems Life Technologies, Foster City, CA, USA), according to a standardized protocol. The qPCR was performed at $95^{\circ} \mathrm{C}$ for $10 \mathrm{~min}$, followed by 40 cycles of $10 \mathrm{sec}$ at $95^{\circ} \mathrm{C}$ and an interval of $1 \mathrm{~min}$ at $60^{\circ} \mathrm{C}$.

MiRNA-7 transfection. The cells were plated in 6-well plates in phenol red-free RPMI-1640 media, supplemented with $10 \%$ dextran-coated charcoal FBS (Life Technologies). Transient transfections were performed with $10 \mathrm{nM}$ miR-7 (has-miR-7; 5'-UGGAAGACUAGUGAUUUUGUUGU-3') using G-fectin (Genolution Pharmaceutical, Seoul, Korea). A scrambled RNA sequence (5'-AAC AGT CGC GTT TGC GAC TGG-3'; Genolution Pharmaceutical) was used as a negative control. The culture medium was exchanged with miR-7 three days post-transfection. The expression levels of miR-7 were evaluated using $\mathrm{qPCR}$, as described above, on the fifth day following the initial transfection. The primer sequences used for the qPCR were as follows: Forward, 5'-GGGCCCGCTCTAGACT CGAGATATTTGCATGTCGCTATGTG-3' and reverse, 5'-CGCGGCCGCCTAATGGATCCAAAAAAGGCACAGT CGAGGCTGATC-3'.

Bioinformatics analysis of miRNA expression data. TargetScan (http://www.targetscan.org/), Microcosm Targets (http://www. ebi.ac.uk/enright-srv/microcosm/htdocs/targets/v5/) and microRNA.org (http://www.microrna.org/microrna/home.do) were used to compute miRNA target predictions. Almost all known miRNA binding site are located in the $3^{\prime}$ untranslated region of target mRNA, and the target databases contained mRNA conserved binding sites of miRNA.

Western blotting. The cells were lysed in radioimmunoprecipitation assay buffer $(150 \mathrm{mM} \mathrm{NaCl}, 1 \% \mathrm{NP}-40$, $50 \mathrm{mM}$ Tris- $\mathrm{HCl} \mathrm{pH}$ 7.4, $1 \mathrm{mM}$ phenylmethylsulfonyl fluoride, $1 \mu \mathrm{g} / \mathrm{ml}$ leupeptin, $1 \mathrm{mM}$ deoxycholic acid and $1 \mathrm{mM}$ EDTA) containing a cocktail of protease and phosphatase inhibitors (Merck Millipore, Darmstadt, Germany). The cells were then centrifuged and lysed in lysis buffer containing $20 \mathrm{mM}$ Tris- $\mathrm{HCl}$ (pH 7.4), $150 \mathrm{mM} \mathrm{NaCl}, 1 \mathrm{mM}$ EDTA, $1 \mathrm{mM}$ EGTA, $5 \mathrm{mM} \mathrm{NaF}, 1 \approx \mathrm{mM}$ orthovanadate, $10 \%$ (vol/vol) glycerol, $1 \%$ Triton X-100, 0.5\% Nonidet P-40, $1 \mathrm{mM}$ phenylmethylsulfonyl fluoride, $2 \mu \mathrm{g} / \mathrm{ml}$ leupeptin, and $10 \mu \mathrm{g} / \mathrm{ml}$ aprotinin (Life Technologies). The samples were cleared by centrifugation at $13,500 \times \mathrm{g}$ at $4^{\circ} \mathrm{C}$ for $10 \mathrm{~min}$, and protein concentrations were determined using a Bio-Rad protein assay (Bio-Rad Laboratories, Inc., Hercules, CA, USA). Equal amounts of protein samples (30-50 $\mu \mathrm{g})$ were separated by $12 \%$ SDS-PAGE and transferred to polyvinylidene fluoride membranes (EMD Millipore), using the Bio-Rad semi-dry transfer system (Bio-Rad Laboratories, Inc.).

Statistical analysis. To determine significance between the groups, paired or unpaired t-tests were performed, depending on the experimental specifications. Normality assumptions were assessed by Shapiro-Wilks tests. When the normality assumption could not be held, paired or unpaired Wilcoxon rank-sum tests were performed. All of the analyses were conducted using SAS version 9.2 (SAS Institute Inc., Cary, NC, USA) or SPSS version 13.0 (SPSS Inc., Chicago, IL, USA). A value of $\mathrm{P}<0.05$ was considered to indicate a statistically significant difference.

\section{Results}

Gefitinib-resistant cell lines, maintained on gefitinib, stably exhibited higher $I C_{50}$ values. Gefitinib-resistant subclones had 3 -fold greater $\mathrm{IC}_{50}$ values, as compared with their parent counterparts (Fig. 1), as determined by cytotoxicity assays. To determine the stability of gefitinib resistance in the gefitinib-resistant sub-clones, the $\mathrm{IC}_{50}$ values were compared between the normally maintained gefitinib-resistant sub-clones and the resistant sub-clones which were subsequently cultured in gefitinib-free medium for three weeks. Following the three weeks of gefitinib-free culturing, there were no statistically significant changes to the $\mathrm{IC}_{50}$ values.

Morphological differences between parent and gefitinib-resistant cell lines. Gefitinib-resistant sub-clones grew slower, as compared with the parent cells. The resistant cell lines exhibited an enlarged and flattened cell morphology, resembling that of cell senescence, as compared with the parent cells, but only following numerous generations. Conversely, acute exposure to high doses of gefitinib did not result in morphological changes. The morphologic changes observed in the A549 gefitinib-resistant cells included spindle-shaped cells, with loss of polarity and increased formation of pseudopodia (Fig. 2).

MiRNA array profiling and bioinformatics analyses. A microarray platform was optimized for the analysis of a panel of human miRNAs, and was used to analyze and compare the pattern of miRNA expression between the parent and gefitinib-resistant A549 cells. The expression profiles of 43 miRNAs changed significantly (2.0-14.0 fold), with 25 upregulated miRNAs and 18 downregulated miRNAs detected in the resistant cells, as compared with the parent cells (Table I). Six specific miRNAs, with the most 
A

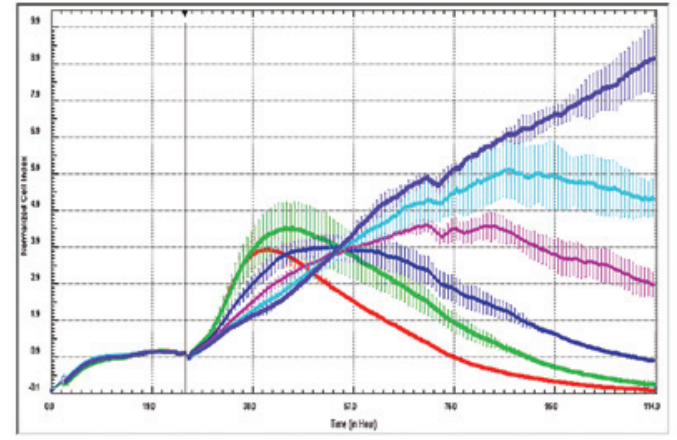

B

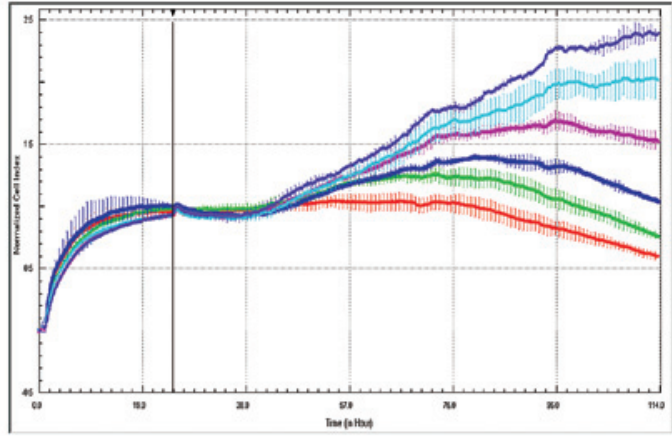

C

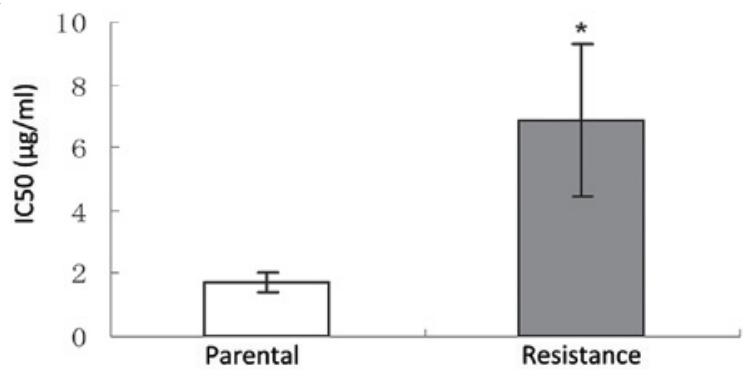

Figure 1. Paired half maximal inhibitory concentration $\left(\mathrm{IC}_{50}\right)$ calculations were conducted to verify gefitinib resistance. Gefitinib was added to the control and developed resistance A549 lung cancer cells at $24 \mathrm{~h}$, with multiple graded concentrations. (A) Control cell line response to gefitinib treatment. (B) Resistant cell line response to gefitinib treatment. (C) $\mathrm{IC}_{50}$ values, as determined using integrated software, with equation area-under-curve dose-response. ${ }^{*} \mathrm{P}<0.05$.

A

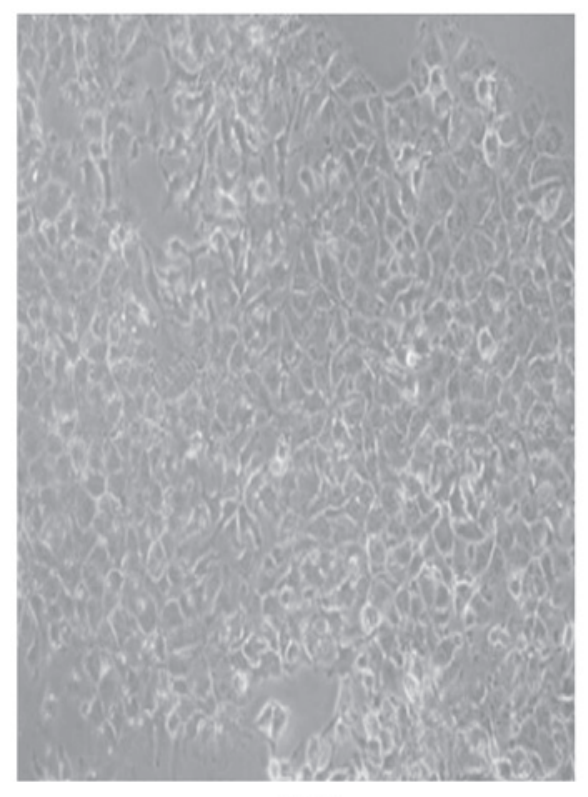

A549
B

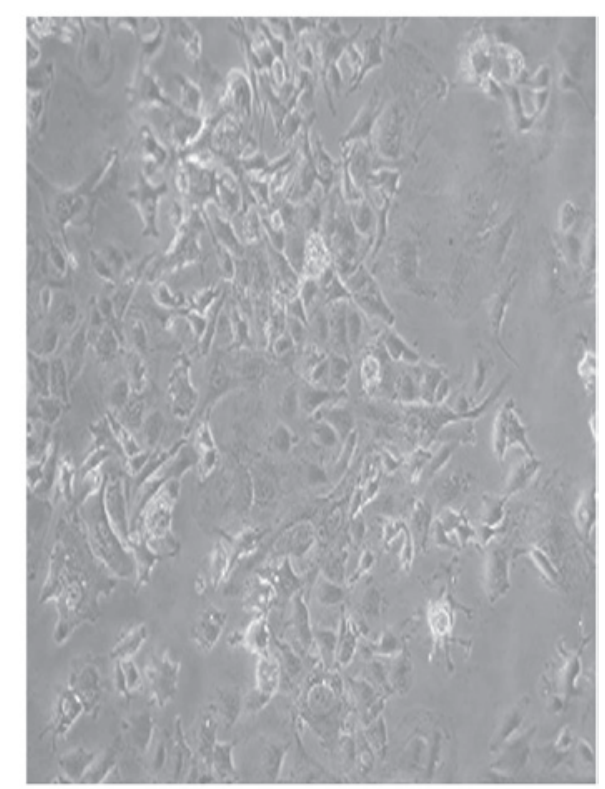

A549 gefitinib resistant sub-clone

Figure 2. Morphological changes in the gefitinib-resistant A549 lung cancer cell line. (A) The cells were seeded onto a chamber slide and stained with hematoxylin \& eosin. (A) The A549 parent and (B) Gefitinib-resistant cells were evaluated for morphological changes. Magnification, 1x200.

significantly altered expression levels between the groups, were chosen to be verified using qPCR, and concordant results were obtained (Fig. 3).

MiR-7 transfection reversed drug sensitivity in the gefitinib resistant cell line. The analysis of potential target genes of miR-7 were evaluated using TargetScan, Microcosm Targets, and microRNA.org target prediction software. The results indicated EGFR as one of the target genes of miR-7. Therefore, in the present study, the correlation between EGFR and miR-7 expression was determined. In order to confirm the effects of miR-7 mimics on miRNA expression, miR-7 expression levels were determined using qPCR. MiR-7 expression levels were significantly upregulated following transfection with miR-7, whereas the expression levels were significantly downregulated in the gefitinib-resistant cells 
Table I. Differential expression levels of micro (mi)RNAs in the gefitinib-resistant sub-clone and parent A549 lung cancer cells (resistance/parent).

\begin{tabular}{|c|c|c|c|}
\hline No. & miRNA & Fold change $^{\mathrm{a}}(\log 2)$ & P-value \\
\hline 1 & miR-21 & 13.234 & 0.0032 \\
\hline 2 & $\operatorname{miR}-124 c$ & 11.422 & 0.0051 \\
\hline 3 & miR-181 & 11.233 & 0.0178 \\
\hline 4 & $\operatorname{miR}-214$ & 9.966 & 0.0020 \\
\hline 5 & $\operatorname{miR}-31$ & 8.434 & 0.0411 \\
\hline 6 & miR-148a & 8.234 & 0.0069 \\
\hline 7 & miR-299-5p & 8.012 & 0.0260 \\
\hline 8 & miR-127 & 6.987 & 0.0145 \\
\hline 9 & miR-660 & 6.782 & 0.0071 \\
\hline 10 & miR-22 & 6.340 & 0.0124 \\
\hline 11 & miR-24-1 & 5.233 & 0.0048 \\
\hline 12 & miR-766 & 5.123 & 0.0021 \\
\hline 13 & miR-762 & 5.076 & 0.0161 \\
\hline 14 & miR-143 & 4.671 & 0.0052 \\
\hline 15 & miR-376a & 4.234 & 0.0225 \\
\hline 16 & miR-99a & 4.123 & 0.0146 \\
\hline 17 & miR-132 & 4.098 & 0.0301 \\
\hline 18 & miR-145 & 3.567 & 0.0169 \\
\hline 19 & miR-125b & 3.123 & 0.0024 \\
\hline 20 & miR-130a & 2.987 & 0.0071 \\
\hline 21 & $\operatorname{miR}-423-5 p$ & 2.871 & 0.0176 \\
\hline 22 & miR-497 & 2.456 & 0.0248 \\
\hline 23 & $\operatorname{miR}-375$ & 2.344 & 0.0008 \\
\hline 24 & miR-744 & 2.123 & 0.0013 \\
\hline 25 & $\operatorname{miR}-140-3 p$ & 2.098 & 0.0340 \\
\hline 26 & miR-7 & -14.098 & 0.0043 \\
\hline 27 & miR-146a & -9.856 & 0.0237 \\
\hline 28 & miR-142-5p & -9.678 & 0.0198 \\
\hline 29 & miR-122 & -7.345 & 0.0260 \\
\hline 30 & miR-126 & -5.345 & 0.0103 \\
\hline 31 & $\operatorname{miR}-424$ & -5.231 & 0.0071 \\
\hline 32 & miR-494 & -5.013 & 0.0342 \\
\hline 33 & $\operatorname{miR}-224$ & -4.875 & 0.0304 \\
\hline 34 & miR-155 & -4.456 & 0.0102 \\
\hline 35 & miR-638 & -4.123 & 0.0051 \\
\hline 36 & miR-483-3p & -4.091 & 0.0178 \\
\hline 37 & miR-92a & -3.987 & 0.0003 \\
\hline 38 & miR-505 & -3.675 & 0.0311 \\
\hline 39 & miR-125-3p & -3.102 & 0.0254 \\
\hline 40 & miR-572 & -2.514 & 0.0260 \\
\hline 41 & miR-100 & -2.287 & 0.0175 \\
\hline 42 & miR-720 & -2.173 & 0.0091 \\
\hline 43 & let-7e & -2.098 & 0.0105 \\
\hline
\end{tabular}

a|Fold change $\mid>2$ was listed. Fold change $=$ resistance/parent.

without miR-7 transfection, as compared with the control cells (Fig. 4A). Western blotting results revealed that EGFR protein expression levels were considerably reduced in the
miR-7 mimic-transfected cells following gefitinib treatment, as compared with the resistant cells without miR-7 transfection (Fig. 4B). 


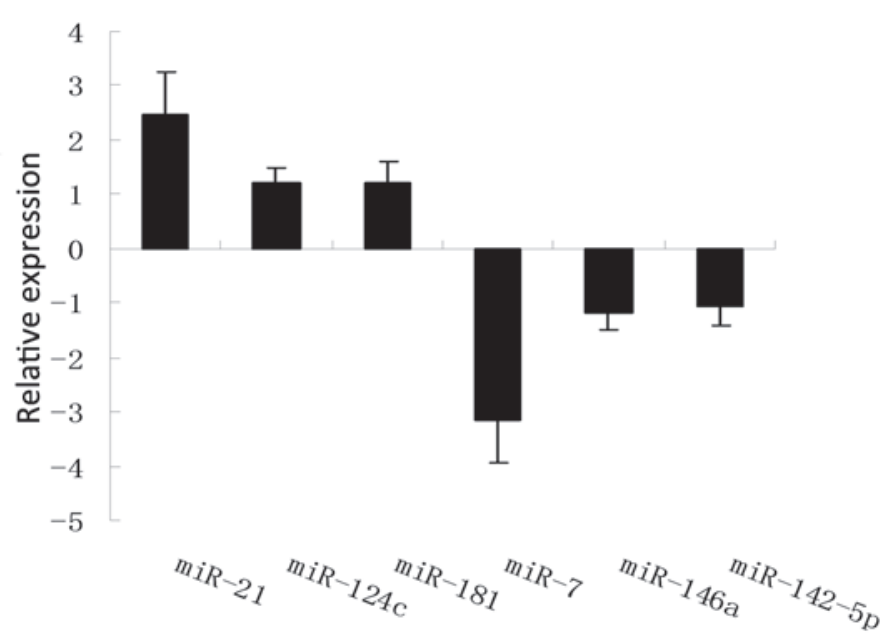

Figure 3. Validation of microarray results. A quantitative polymerase chain reaction was performed to determine the expression levels of six representative microRNAs (miR), which were previously indicated to have the most altered expression levels in the gefitinib-resistant A549 lung cancer cells. The results were concordant with the microarray results. Error bars represent the standard deviation.

A

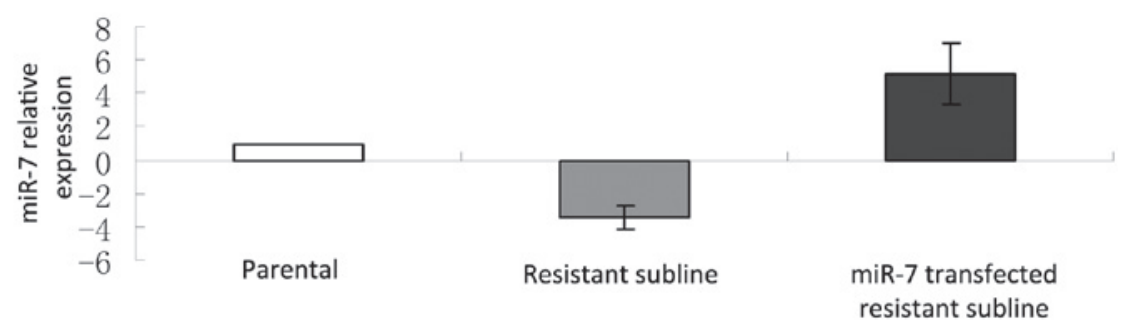

B

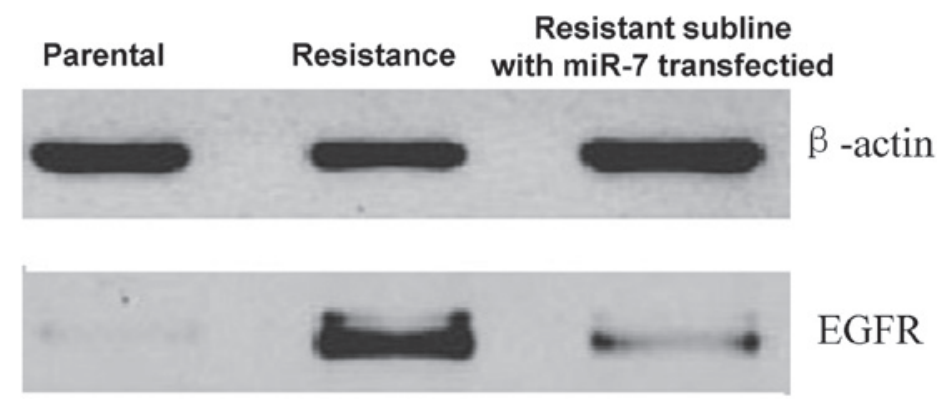

Figure 4. Validation of micrRNA-7 (miR-7) transfection efficiency. (A) Relative expression levels of miR-7, as determined by quantitative polymerase chain reaction. Significant upregulation of miR-7 expression levels was detected following transfection of the gefitinib-resistant A549 lung cancer cells with a miR-7 mimic, whereas significant downregulation was detected in the resistant cells without miR-7 transfection, as compared with the control cells. U6 was used as the internal control. (B) Western blot analysis detected no expression of epidermal growth factor receptor (EGFR) protein in the parent cells, whereas EGFR protein expression was markedly decreased following gefitinib treatment in the miR-7 mimic-transfected resistant cells, as compared with the resistant cells without miR-7 transfection.

\section{Discussion}

Chemotherapy remains the main therapeutic option for the treatment of NSCLC. However, despite a good initial response to therapy, most NSCLC patients suffer from the development of chemoresistance and relapse (15). Therefore, development of novel targeting specific molecules to attenuate drug resistance, and establishment of rational therapeutic approaches are required. Microarray analysis has made it possible to identify appropriate candidate molecules for such purposes (16). In the present study a gefitinib-resistant cell line was successfully established from the widely used A549 lung cancer cell line. Cellular models of NSCLC in vitro are based on assays using sensitive and resistant cell lines to chemotherapy, in order to mimic the clinical scenario. Comprehensive miRNA expression profiles of NSCLC were obtained using a miRNA microarray and the functions of the identified miRNA were evaluated.

As well as the conventional end-point cytotoxicity measurements, a label-free approach was used to determine the 
cytotoxic response of adherent cells in real time, as previously described (17). In the present study, the real-time cell analyzer system xCELLigence (RTCA-SP) was used to continuously monitor cellular growth and death, revealing the physiological states of the cells throughout the process of gefitinib treatment. The parent and developed resistant cell lines exhibited different growth curves and drug responses, when seeded at the same density. The morphological changes in the gefitinib-resistant A549 cells observed in the present study were concordant with those observed in a previous report (18). The gefitinib-resistant cells were larger and more cellular vacuolation, as compared with the parent cells; however, the shape of the resistant cells were polygonal, which was similar to the parent cells.

Evidence regarding the roles of miRNAs in determining drug sensitivity and resistance in lung cancer has recently been emerging (19). A previous study demonstrated that the miR-134/487b/655 cluster contributed to transforming growth factor- $\beta 1$-induced epithelial-mesenchymal transition (EMT) and affected the resistance to gefitinib by directly targeting the membrane-associated guanylate kinase, WW and PDZ domain-containing protein 2 (MAGI2). The suppression of MAGI2 subsequently resulted in the loss of phosphatase and tensin homolog stability in lung cancer cells. This resulted in the suggestion that the miR-134/miR-487b/miR-655 cluster may be a novel potential therapeutic target in advanced lung adenocarcinoma patients, affecting the EMT phenomenon (20). Dong et al (21) previously determined that miR-31 was significantly upregulated in a cisplatin-resistant lung cancer cell line, as compared with a cisplatin-sensitive cell line. This study also demonstrated that miR-31 is capable of conferring cisplatin-induced apoptosis and that inhibition of ABCB9 is essential for cisplatin resistance. Using miRNA microarray analysis, An et al (22) identified 24 miRNAs displaying differential expression levels, greater than 2-fold, in Rh2-treated A549 cells, as compared with their respective parent cell lines. Aberrant miRNA expression has also been detected for miR-30b, miR-30c, miR-221 and miR-222, which may have important roles in gefitinib-induced apoptosis and EMT of NSCLC cells in vitro and in vivo. These effects may be mediated through inhibiting the expression of the genes encoding BCL2-like 11, apoptotic peptidase activating factor 1, protein kinase $\mathrm{C} \varepsilon$ and sarcoma viral oncogene homolog (23).

In the present study, a miRNA expression profile detected a differential expression pattern between gefitinib-resistant and gefitinib-sensitive A549 cells. Of the miRNA genes analyzed, 43 miRNAs were significantly altered between the cell lines (>2-fold), including the upregulation of 25 and downregulation of 18 miRNAs. The differential expression levels of these miRNAs in the cells suggests a role for these miRNAs in the development of drug resistance in NSCLC cells.

miR-7 has previously been reported to inhibit EGFR expression and subsequently suppress cell proliferation in numerous human carcinoma cell lines $(24,25)$. Bioinformatic predictions suggest that the human EGFR mRNA 3'-untranslated region contains three miR-7 target sites, which are not conserved across mammals (26). In Drosophila photoreceptor cells, miR-7 controls EGFR signaling and promotes photoreceptor differentiation (27). The other targets of miR-7 include insulin-like growth factor-1 receptor (IGF1R) and PIK3CD (28), the E(spl) gene family (29) and Pak1 cancer cells (30). In a previous study of breast cancer, miR-7 was suggested to have a role in the development of resistance to endocrine therapy in breast cancer patients, through regulating the expression of EGFR in carcinoma cells (31). MiR-7 has also been reported to regulate IGF-1R expression in tongue squamous cell carcinoma cells (28). In the present study, EGFR was negatively regulated by miR-7 mimic transfection, and downregulation of EGFR expression at the protein level largely correlated with elevated levels of miR-7 in the gefitinib-resistant cells. The results of the present study suggest that miR-7 may have central roles in the development of resistance to endocrine therapy in resistant cells through regulating the expression of EGFR in cancer cells.

In conclusion, the present study demonstrated that specific miRNAs may be differentially expressed in drug-resistant NSCLC cells, thereby suggesting their involvement in the generation of the drug-resistant phenotype. The specific miRNA, miR-7 was implicated, which targets the expression of EGFR. The results indicate the potential use of these miRNAs as specific diagnostic biomarkers for drug sensitivity of NSCLC. An in vitro model may not explain resistance in patients, but remains a critical initial step in studying the mechanisms of gefitinib resistance. MiRNA signatures require further validation in clinical samples from NSCLC patients. The results of the present study provide the foundation for future research into biomarkers associated with gefitinib resistance, which may ultimately lead to an improved rationale for personalized chemotherapy selection.

\section{Acknowledgements}

The present study was supported by the Guizhou Province Programs for Science and Technology Development.

\section{References}

1. Jemal A, Siegel R, Xu J and Ward E: Cancer statistics, 2010. CA Cancer J Clin 60: 277-300, 2010

2. Mendlsohn $\mathbf{J}$ and Baserga J: The EGF receptor family as targets for cancer therapy. Oncogene 19: 6550-6565, 2000.

3. Fukuoka M, Yano S, Giaccone G, et al: Multi-institutional randomized phase II trial of gefitinib for previously treated patients with advanced non-small-cell lung cancer (The IDEAL 1 Trial) [corrected]. J Clin Oncol 21: 2237-2246, 2003.

4. Kris MG, Natale RB, Herbst RS, et al: Efficacy of gefitinib, an inhibitor of the epidermal growth factor receptor tyrosine kinase, in symptomatic patients with non-small cell lung cancer: a randomized trial. JAMA 290: 2149-2158, 2003.

5. Nakagawa K, Tamura T, Negoro S et al: Phase I pharmacokinetic trial of the selective oral epidermal growth factor receptor tyrosine kinase inhibitor gefitinib ('Iressa', ZD1839) in Japanese patients with solid malignant tumours. Ann Oncol 14: 922-930, 2003.

6. Jackman D, Pao W, Riely GJ, et al: Clinical definition of acquired resistance to epidermal growth factor receptor tyrosine kinase inhibitors in non-small-cell lung cancer. J Clin Oncol 28: 357-360, 2010.

7. Peled N, Wynes MW, Ikeda N, et al: Insulin-like growth factor-1 receptor (IGF-1R) as a biomarker for resistance to the tyrosine kinase inhibitor gefitinib in non-small cell lung cancer. Cell Oncol (Dordr) 36: 277-288, 2013.

8. Roybal JD, Zang Y, Ahn YH, et al: miR-200 inhibits lung adenocarcinoma cell invasion and metastasis by targeting Flt1/VEGFR1. Mol Cancer Res 9: 25-35, 2011.

9. Esquela-Kerscher A, Trang P, Wiggins JF, et al: The let-7 microRNA reduces tumor growth in mouse models of lung cancer. Cell Cycle 7: 759-764, 2008.

10. Ambros V: microRNAs: tiny regulators with great potential. Cell 107: 823-826, 2001. 
11. Hwang HW and Mendell JT: MicroRNAs in cell proliferation, cell death, and tumorigenesis. Br J Cancer 94: 776-780, 2006.

12. Leung AK and Sharp PA: microRNAs: a safeguard against turmoil? Cell 130: 581-585, 2007.

13. Coldren CD, Helfrich BA, Witta SE, et al: Baseline gene expression predicts sensitivity to gefitinib in non-small cell lung cancer cell lines. Mol Cancer Res 4: 521-528, 2006.

14. Uphoff CC and Drexler HG: Detecting mycoplasma contamination in cell cultures by polymerase chain reaction. Methods Mol Biol 731: 93-103, 2011.

15. Gainor JF and Shaw AT: Emerging paradigms in the development of resistance to tyrosine kinase inhibitors in lung cancer. J Clin Oncol 31: 3987-3996, 2013.

16. Guo L, Liu Y, Bai Y, Sun Y, Xiao F and Guo Y: Gene expression profiling of drug-resistant small cell lung cancer cells by combining microRNA and cDNA expression analysis. Eur J Cancer 46: 1692-1702, 2010.

17. Nguemo F, Šarić T, Pfannkuche K, Watzele M, Reppel M and Hescheler J: In vitro model for assessing arrhythmogenic properties of drugs based on high-resolution impedance measurements. Cell Physiol Biochem 29: 819-832, 2012

18. Rho JK, Choi YJ, Lee JK, et al: Epithelial to mesenchymal transition derived from repeated exposure to gefitinib determines the sensitivity to EGFR inhibitors in A549, a non-small cell lung cancer cell line. Lung Cancer 63: 219-226, 2009

19. Maftouh M, Avan A, Galvani E, Peters GJ and Giovannetti E: Molecular mechanisms underlying the role of microRNAs in resistance to epidermal growth factor receptor-targeted agents and novel therapeutic strategies for treatment of non-small-cell lung cancer. Crit Rev Oncog 18: 317-326, 2013.

20. Kitamura K, Seike M, Okano T, et al: MiR-134/487b/655 cluster regulates TGF- $\beta$-induced epithelial-mesenchymal transition and drug resistance to gefitinib by targeting MAGI2 in lung adenocarcinoma cells. Mol Cancer Ther 13: 44-453, 2014.
21. Dong Z, Zhong Z, Yang L, Wang S and Gong Z: MicroRNA-31 inhibits cisplatin-induced apoptosis in non-small cell lung cancer cells by regulating the drug transporter ABCB9. Cancer Lett 343: 249-257, 2014.

22. An IS, An S, Kwon KJ, Kim YJ and Bae S: Ginsenoside Rh2 mediates changes in the microRNA expression profile of human non-small cell lung cancer A549 cells. Oncol Rep 29: 523-528, 2013.

23. Garofalo M, Romano G, Di Leva G, et al: EGFR and MET receptor tyrosine kinase-altered microRNA expression induces tumorigenesis and gefitinib resistance in lung cancers. Nat Med 18: 74-82, 2011.

24. Kefas B, Godlewski J, Comeau L, et al: microRNA-7 inhibits the epidermal growth factor receptor and the Akt pathway and is down-regulated in glioblastoma. Cancer Res 68: 3566-3572, 2008.

25. Giles KM, Barker A, Zhang PM, Epis MR and Leedman PJ: MicroRNA regulation of growth factor receptor signaling in human cancer cells. Methods Mol Biol 676: 147-163, 2011.

26. Webster RJ, Giles KM, Price KJ, Zhang PM, Mattick JS and Leedman PJ: Regulation of epidermal growth factor receptor si gnaling in human cancer cells by microRNA-7. J Biol Chem 284: 5731-5741, 2009

27. Li X and Carthew RW: A microRNA mediates EGF receptor signaling and promotes photorecepotor differentiation in the Drosophila eye. Cell 123: 1267-1277, 2005.

28. Jiang L, Liu X, Chen Z, et al: MicroRNA-7 targets IGF1R (insulin-like growth factor 1 receptor) in tongue squamous cell carcinoma cells. Biochem J 432: 199-205, 2010.

29. Stark A, Brennecke J, Russell RB and Cohen SM: Identification of Drosophila microRNA targets. PLoS Biol 1: E60, 2003

30. Reddy SD, Ohshiro K, Rayala SK and Kumar R: MicroRNA-7, a homeobox D10 target, inhibits p21-activated kinase 1 and regulates its functions. Cancer Res 68: 8195-8200, 2008

31. Masuda M, Miki Y, Hata S, et al: An induction of microRNA, miR-7 through estrogen treatment in breast carcinoma. J Transl Med 10: S2, 2012. 